\title{
Structural equation model of affecting factors on elder abuse to patients under hemodialysis by family caregivers
}

\author{
Amaneh Mahmoudian ${ }^{1,2}$, Abbas Shamsalinia ${ }^{3}$, Atefeh Alipour ${ }^{4}$, Zahra Fotoukian ${ }^{2}$ and Fatemeh Ghaffari ${ }^{*}$
}

\begin{abstract}
Background: The objectives of the present study were to determine the prevalence of older adults with hemodialysis (HD) abuse by family caregivers and the factors affecting it.

Method: This is a correlational-causal study, which is conducted in 2018 in Iran. The sample size was 367 in both groups (the older adults and their family caregivers). Data collection was done using an individual-social information questionnaire for the older adults under hemodialysis and their family caregivers, the questionnaire of elder abuse by family caregivers to the older people under hemodialysis, Zarit Burden Interview and the scale of instrumental activities of daily living (IADL). Data were analyzed by the structural equation model (SEM) method. The Fitness of proposed pattern was measured using the following indexes: chi-square/degree of freedom ratio (CMIN/DF), Normed Fit Index (NFI), comparative fit index (CFI), goodness of fit index (GFI), and standardized root mean squared residual (SRMR). The significant level in this study was considered $p<0.05$.
\end{abstract}

Results: The results of the present study showed that more than $70 \%$ of the older adults suffer from elder abuse by family caregivers on average. The highest median elder abuse was related to emotional misbehavior $(21.46 \pm 6.09)$ and financial misbehavior (19.07 \pm 5.33$)$, respectively. Moderate care burden was experienced by $63.2 \%$ of caregivers. The percentage of older women and men, who needed help with daily activities was 81.4 and $80.5 \%$, respectively. The results showed that the caregivers' level of education and care burden with standard beta coefficient of -0.251 and 0.200 and the educational level of older adults and IADL with the best beta coefficient of -0.299 and -0.234 , had the highest regression effect on elder abuse respectively. According to the results, the model-fit indices of the hypothesized model was meet the criteria, with the $\mathrm{NFI}=0.951, \mathrm{GFI}=0.970, \mathrm{CFI}=0.967$, and $\mathrm{SRMR}=0.041$. The outcome was suitable for the recommended level, so the hypothetical model appeared to fit the data.

Conclusions: The results of the present study showed that the prevalence of elder abuse by family caregivers among the older adults under hemodialysis is high. Providing psychological counseling can reduce the consequences of elder abuse.

Keywords: Elder abuse, Older adults, Family caregivers, Chronic kidney disease, End stage kidney disease, Hemodialysis

\footnotetext{
* Correspondence: ghafarifateme@yahoo.com

${ }^{2}$ Nursing Care Research Center, Health Research Institute, Babol University of Medical Sciences, Shahid Motahari St, Ramsar, Mazandaran, Ramsar, Iran

Full list of author information is available at the end of the article
}

\section{$\triangle B M C$}

(c) The Author(s). 2021 Open Access This article is licensed under a Creative Commons Attribution 4.0 International License, which permits use, sharing, adaptation, distribution and reproduction in any medium or format, as long as you give appropriate credit to the original author(s) and the source, provide a link to the Creative Commons licence, and indicate if changes were made. The images or other third party material in this article are included in the article's Creative Commons licence, unless indicated otherwise in a credit line to the material. If material is not included in the article's Creative Commons licence and your intended use is not permitted by statutory regulation or exceeds the permitted use, you will need to obtain permission directly from the copyright holder. To view a copy of this licence, visit http://creativecommons.org/licenses/by/4.0/ The Creative Commons Public Domain Dedication waiver (http://creativecommons.org/publicdomain/zero/1.0/) applies to the data made available in this article, unless otherwise stated in a credit line to the data. 


\section{Background}

The global population of people aged 60 years old and older is expected to grow from 900 million in 2015 to almost 2 billion in 2050. Therefore, considering the aging population of many countries, the number of older adults who suffer from elder abuse is expected to increase. The world health organization (WHO) estimates that one in six older people aged 60 and older will experience elder abuse [1]. In a systematic review conducted by Ghiasi et al. (2018) in Iran, the total rate of elder abuse was reported to be between 14.7 and $87.8 \%$ [2]. Molaei et al. (2017) also reported a $56.4 \%$ prevalence of the subject among the Iranian older adults [3].

According to the centers for disease control and prevention (CDC), elder abuse is an intentional act or failure to act that causes or creates a risk of harm to an older adult or violates the human rights and reduces the life quality of an older adult (over 60 years) [4]. Human rights violations include physical, sexual, psychological and emotional misbehaviors, as well as financial and material abuse, abandonment, neglect and a serious lack of dignity and respect toward the older adult [5].

Although elder abuse may occur by HCPs, employees of long-term care centers for the older adults, or any other citizen, the abuse by family caregivers can have far-reaching consequences. Identifying and managing such abuses and the many challenges associated with it is a priority for public health and a major concern for health policymakers [6]. The increase in the prevalence of chronic and often disabling diseases among the older adults is associated with functional reduction in daily activities which lead to more dependence on HCPs and family caregivers [7]. Older people's dependence on caregivers, along with poor health and chronic conditions, may expose them to abuse, neglect, and violence by family caregivers [8]. Today, due to policies of keeping the older adults at home, the number of older people receiving home care is increasing. In most societies, family members are responsible for caring for them. Caring problems, especially the problems of caring for an older adult, who has extensive care needs due to chronic illness, has increased the likelihood of violence and abuse by family caregivers $[9,10]$.

Findings of Heravi Karimou's research (2011) showed that $25.9 \%$ of the older adults have experienced at least one type of abuse by family caregivers. The highest prevalence of behavioral abuse was related to emotional neglect $(17.4 \%)$ and psychological abuse $(17.2 \%)$ and the lowest was related to rejection (3.7\%) and physical abuse $(7.4 \%)$ [11]. The results of a study by Rahimi et al. (2016) also showed that $62.8 \%$ of the older adults have experienced caring negligence, $41 \%$ mental abuse, $27.4 \%$ physical abuse, $36.7 \%$ financial misbehaviour, $48.6 \%$ deprivation of authority, $25.6 \% \%$ rejection,
$36.5 \%$ financial negligence and $36 \%$ have experienced emotional negligence [12]. Elder abuse in the family is defined as the imposition of pain and suffering on the older adults by family members, which may occur intentionally or unintentionally by committing an annoying act or leaving a necessary act intentionally or unintentionally, once or for a couple of times [13]. Elder abuse by family caregivers depends on a variety of factors, such as caregiver-related factors or patient-related factors. In their studies, a number of researchers have pointed to the effective factors of elder abuse. For instance, Yan et al. (2011) consider factors such as the number of days of living together and rejecting the help of domestic helper as well as the burden of care as predictors for elder abuse [14]. Rahimi et al. (2016) also considered age, number of children, amount of income and marital status as the effective factors in abuse and neglect of an older adult by family members [12].

Chronic kidney disease (CKD) and related therapies such as hemodialysis are one of the factors that may provide grounds for abuse in various dimensions [15]. The incidence of CKD has increased due to the increasing population of the older adults, the high prevalence of diabetes, hypertension and cardiovascular disease in the world [16].

Since the elder abuse can be associated with serious physical harms and long-term psychological consequences such as physical damages, loss of efficiency, social isolation, despair, hopelessness, depression, and reduced life, health and safety satisfaction in the older people [17]. Recognition of the influencing factors on this phenomenon can lead to a reduction in the possible serious consequences of it. However, despite the world health organization's emphasis on international awareness on identifying and preventing elder abuse, the influencing factors for different groups with different backgrounds are still unknown. As the elder abuse by family caregivers is multifactorial and can depend on culture, nature of the disease, and the individual, social and clinical characteristics of the older adults and their family caregivers [18], it is therefore necessary to recognize the factors influencing on the phenomenon based on cultural contexts and individual backgrounds, so that intervention programs can be developed and implemented $[5,19]$.

In Iran, cultural barriers and the lack of support systems have prevented most elderly people, especially hemodialysis patients, from reporting cases of elder abuse to HCPs at the time of admission to clinical centers and during the treatment process. These barriers have made HCPs reluctant to investigate and report cases of elder abuse [20, 21]. Studies that examined the prevalence of elder abuse and its related factors in this group of Iranian older population were also not found 
during the literature review. Recognizing this problem and the factors influencing it can help HCPs to consider elder abuse and related factors in their care priorities and make evidence-based interventions.

\section{This study aimed to:}

1- Determining the prevalence of elder abuse to patients under hemodialysis by family caregivers and

2- Determining the effective factors in the elder abuse to patients under hemodialysis by family caregivers.

\section{Research questions include:}

1- What is the prevalence of elder abuse among the patients under hemodialysis by family caregivers.

2- What are the effective factors in the elder abuse to patients under hemodialysis by family caregivers.

\section{Methods}

\section{Design}

This is a correlational-causal study conducted in 2018 in Iran.

\section{Sample}

The study population was all the older people under hemodialysis who referred to medical centers in the western cities of Mazandaran province and the eastern part of Gilan province and their family caregivers.

The total number of hemodialysis patients in the east of Guilan and west of Mazandaran provinces was 563, of which 402 were 60 years old and older. There were 412 family caregivers. Convenience sampling was applied and the number of samples was determined using the following formula.

$$
n=\frac{2\left(Z_{1-\frac{\alpha}{2}}+Z_{1-\beta}\right)^{2} s^{r}}{d^{r}}
$$

is the needed sample size, $\mathrm{s}=24.5$ and $\mathrm{d}=0.2 \mathrm{~s}$. The needed sample size was stimated to be 341 participants by accepting $\alpha=0.05, Z_{1-\frac{\alpha}{2}}=1.96,80 \%$ of sample power and $Z_{1-\beta}=0.84$. Taking into account the $10 \%$ probability of sample loss, the number of sample size for each group of hemodialysis older adults and their family caregivers was considered to be 370 people.

\section{Inclusion criteria}

For older adults: being 60 and older, history of hemodialysis for at least one year, not having confirmed mental illness, lack of sensory disturbances such as blindness and deafness and receiving the score of 7 and above at the abbreviated mental test [19].
For caregiver: caring for an older adult under hemodialysis, being the patient's relative, not caring another older adults and not having physical or mental illnesses (self-report).

\section{Exclusion criteria \\ Unwillingness for cooperation.}

\section{Data collection}

The research tool was completed through interviews for the elderly group, but self-administered by the family caregiver group. Data was collected by the following tools:

\section{1- Individual-social information questionnaire related to older people under hemodialysis}

Age, sex, marital status, level of education, number of children, occupation, roommate, frequent hospitalization due to chronic illness, having other chronic diseases, duration of hemodialysis, being the head of family, ability of doing personal activities, level of need for daily care, member of the hemodialysis association, drug abuse, financial sufficiency and type of medical insurance.

\section{2- Individual-social information questionnaire related to family caregivers}

Age, sex, marital status, level of education, medical education, being patient's relative, length of care for the older adults, chronic illness, care for another patient, being the source of family income, place of residence, housing status, occupation, number of family members, living with the patient.

\section{The questionnaire of Elder Abuse to the patients under hemodialysis by Family Caregivers}

This tool has been designed and psychometrically assessed by Mahmoudian et al. (2018). It has an acceptable internal validity $(\alpha=0.98)$ for measuring the construct of elder abuse by family caregivers. It includes 57 items and 7 subscales including psychological misbehavior (6items), authority deprivation (7items) physical misbehaviours ( 2 items), financial misbehaviours (11 items), being abandoned (4 items), caring neglect ( 8 items) and emotional misbehavior (19 items). The tool is scored through a 4 point Likert scale with the options of never (1), sometimes (2), often (3) and always (4). Scores range between 1 and 228. Receiving the score of 1-75 indicates low severity of abuse, 76-152 average and 153-228 extreme severity of abuse [15].

\section{4- Zarit Burden Interview}

This tool was designed by Zarit et al. (1988). It includes 22 items and three dimensions of role-playing stress, Intra-psychic stress, and Competencies and expectations. 
Caregiver's responses are assessed through a five point Likert scale (never to always) and the scores range between 0 and 88 . Getting a score of 0 to 20 showed little or no care burden, score of 21 to 40 a moderate, and the score of 41 to 88 a severe care burden [22, 23]. The validity of this tool was investigated and confirmed by Talebi et al. (2016). Its reliability is also confirmed by Cronbach's alpha coefficient of 0.86 [24].

\section{5-Instrumental Activities of Daily Living (IADL)}

This tool was first developed by Lawton \& Brody (1969) and includes 8 dimensions of using of telephone, shopping, meal preparation, housekeeping, laundry, mode of transportation, medication management and money management for women. Women are scored on all 8 areas of function; historically, for men, the areas of food preparation, housekeeping, laundering are excluded. Independent (no help $=2$ ), needs help (with a little help = 1 ) and dependent (cannot do that $=0$ ) based on a 3 point likert scale is used for responding to the questions. A summary score ranges from 0 (low function, dependent) to 8 (high function, independent) for women and 0 through 5 for men. For women, the score of zero indicates a completely dependent situation, 1 to 15 needs for assistance, and the score of 16 indicates a completely independent situation. For men, the score of zero indicates a completely dependent situation, 1 to 9 needs for assistance, and the score of 10 indicates a completely independent situation [25]. The reliability of this tool was controlled by Mehraban et al. (2014). The results showed that the scale has an acceptable validity and the intra-class correlation coefficient of the two stages of the test with $r=0.993$ is confirmed [26].

\section{Data Analysis}

The data obtained from this study were analyzed using AMOS24, SPSS26 softwares and SEM method. SEM is a general and very powerful multivariate analysis technique of the multivariate regression family. More precisely, it is a general linear model, which allows the researcher to test a set of regression equations simultaneously and to Examine the relationships between different variables at the same time [27]. The fitness of the proposed model with data was measured using the chisquare/degree of freedom ratio (CMIN/DF), Normed Fit Index (NFI), comparative fit index (CFI), goodness of fit index (GFI), and Standardized Root Mean Squared Residual (SRMR). P-Value less than 0.05 was considered as significant level.

\section{Results}

Of the 370 samples in the two groups of older people under hemodialysis and their family caregivers, three were excluded from the study due to their refusal to continue cooperation and ignoring a complete revision of the study's tools. Finally, the data of 367 people in both groups were analyzed. The number of patients being 60-65 years old and under hemodialysis was found to be $39 \%$ of the total 367 . Males included $51.5 \%$ of the samples, $32.2 \%$ had a college degree and $67 \%$ were married. Furthermore, $73.6 \%$ of the samples had a history of recurrent hospitalization due to chronic disease (Table 1).

The results showed that the mean and standard deviation of the age of family caregivers was $13.94 \pm 49.85$ years with a minimum of 18 and a maximum of 85 years. Female caregivers accounted for $64.9 \%$ of the total caregivers and $79.8 \%$ were married (Table 2).

The results showed that the average total score of elder abuse by family caregivers was $19.75 \pm 87.89$. The mean total score of abuse severity considering the three levels of low (1-75), moderate (76-152) and extreme (153-228) was $60.53 \pm 5.14,96.2 \pm 9.84$ and $169.66 \pm$ 22.30 respectively. The prevalence of elderly abuse by caregivers is presented in Table 3 according to the severity of the abuse. The results showed that the highest prevalence of elder abuse was related to moderate severity $(70 \%)$.

The results of the present study showed that the mean total score of care burden was $48.63 \pm 16.74$. The mean of the total score for the three severity levels of low (0$20)$, moderate (21-40) and extreme (41-88) were (11.35 \pm 5.59$),(29.28 \pm 5.67)$ and $(53.20 \pm 8.61)$. Also, the highest mean of care burden $(22.61 \pm 8.75)$ was related to the role-related stress aspect. Moderate care burden was experienced by $63.2 \%$ of caregivers (Table 4 ).

The results showed that the mean total IADL scores for men and women were $7.68 \pm 4.85$ and $6.66 \pm 3.62$, respectively. The highest mean scores in older men and women were $1.28 \pm 0.74$ and $1.42 \pm 0.66$, respectively, for medication management aspect. The percentage of older women and men, who needed help with daily activities was 81.4 and $80.5 \%$, respectively (Table 5 ).

The results of Pearson's correlation test showed that there was a significant negative relationship between IADL with care burden $(r=-0.188, P$-value $<0.01)$ and elder abuse $(r=-$ $0.113, P$-value $<0.05)$. There was also a significant positive relationship between care burden and elder abuse $(r=0.285$, $P$-value $<0.01)$. Stepwise method multiple regression was used to investigate the simultaneous effect of variables related to family caregivers and affecting elder abuse. The categorical variables are graded as follows: level of education [illiterate = 0 literate $=1$ ], marital status [single $=0$ married $=1$ ], having a chronic disease $[$ no $=0$ yes $=1]$, medical sciences- related education $[$ no $=0$ yes $=1$ ], financial adequacy [medium down $=0$ up $=1$ ], ability of doing personal activities [medium down $=0$ high $=1$ ], roommate [with spouse and children $=0$ other $=1$. 
Table 1 Demographic characteristics of the older adults under hemodialysis experiencing different severities of elder abuse by family caregivers $(n=367)$

\begin{tabular}{|c|c|c|c|c|c|}
\hline \multirow[t]{2}{*}{ Variable } & \multirow[t]{2}{*}{ Subgroup } & \multirow{2}{*}{$\begin{array}{l}\text { Number } \\
\text { (\%) }\end{array}$} & \multicolumn{3}{|c|}{ Severity of elder abuse by family caregivers } \\
\hline & & & $\begin{array}{l}\text { Low } \\
1-75 \\
\text { Number (\%) }\end{array}$ & $\begin{array}{l}\text { Moderate } \\
76-152 \\
\text { Number (\%) }\end{array}$ & $\begin{array}{l}\text { Extreme } \\
153-228 \\
\text { Number (\%) }\end{array}$ \\
\hline \multirow[t]{6}{*}{ Age (years) } & $60-65$ & 143(39) & $37(10.1)$ & $103(28.1)$ & $3(0.8)$ \\
\hline & $66-70$ & 102(27.8) & $26(7.1)$ & $75(20.5)$ & $0(0)$ \\
\hline & $71-75$ & $65(7.7)$ & 19(5.2) & $46(12.6)$ & $0(0)$ \\
\hline & $76-80$ & $36(9.8)$ & $7(1.9)$ & 29(7.9) & $0(0)$ \\
\hline & $81-85$ & $16(4.4)$ & $5(1.4)$ & $11(3)$ & $0(0)$ \\
\hline & $85<$ & $5(1.4)$ & $2(0.5)$ & $3(0.8)$ & $0(0)$ \\
\hline \multirow[t]{2}{*}{ Sex } & Female & 178(48.5) & $50(13.7)$ & 125(34.2) & $3(0.8)$ \\
\hline & Male & 189(51.5) & $46(12.6)$ & 142(38.8) & $0(0)$ \\
\hline \multirow[t]{4}{*}{ Marital Status } & Single & $5(1.4)$ & $1(0.3)$ & $4(1.1)$ & $0(0)$ \\
\hline & Married & $246(67)$ & $47(12.8)$ & 196(53.6) & $3(0.8)$ \\
\hline & Divorced & $11(3)$ & $10(2.7)$ & $1(0.3)$ & $0(0)$ \\
\hline & Widow & 105(28.6) & $38(10.4)$ & $66(18)$ & $0(0)$ \\
\hline \multirow[t]{5}{*}{ Level of Education } & Illiterate & $167(45.5)$ & $19(5.2)$ & $147(40.2)$ & $1(0.3)$ \\
\hline & Reading and writing & $52(14.2)$ & $14(3.8)$ & $37(10.1)$ & $1(0.3)$ \\
\hline & Primary school & $46(12.5)$ & $11(3)$ & $35(9.6)$ & $0(0)$ \\
\hline & High school & 70(19.1) & $31(8.5)$ & $38(10.4)$ & $1(0.3)$ \\
\hline & University degree & $32(8.7)$ & $21(5.7)$ & $10(2.7)$ & $0(0)$ \\
\hline \multirow[t]{5}{*}{ Number of Children } & No child & $28(7.6)$ & $19(5.2)$ & $9(2.5)$ & $0(0)$ \\
\hline & $1-3$ & $92(25.1)$ & $31(8.5)$ & $58(15.8)$ & $2(0.5)$ \\
\hline & $4-6$ & $175(47.7)$ & $41(11.2)$ & 133(36.3) & $1(0.3)$ \\
\hline & $7-9$ & $61(16.6)$ & $5(1.4)$ & $56(15.3)$ & $0(0)$ \\
\hline & More than 10 & $11(3)$ & $0(0)$ & $11(3)$ & $0(0)$ \\
\hline \multirow[t]{8}{*}{ Occupation } & Unemployed & 49(13.4) & $2(0.5)$ & $47(12.8)$ & $0(0)$ \\
\hline & Farmer & $37(10.1)$ & $9(2.5)$ & $28(7.7)$ & $0(0)$ \\
\hline & Labor & $20(5.4)$ & $4(1.1)$ & $16(4.4)$ & $0(0)$ \\
\hline & Housewife & 105(28.6) & $23(6.3)$ & $79(21.6)$ & $3(0.8)$ \\
\hline & Employee & $12(3.3)$ & $7(1.9)$ & $5(1.4)$ & $0(0)$ \\
\hline & Retired & 73(19.9) & $24(6.6)$ & $48(13.1)$ & $0(0)$ \\
\hline & Self-employed & $26(7.1)$ & 13(3.6) & 13(3.6) & $0(0)$ \\
\hline & Disabled & $45(12.3)$ & 14(3.8) & $31(8.5)$ & $0(0)$ \\
\hline \multirow[t]{5}{*}{ Roommate } & Alone & $50(13.6)$ & $24(6.6)$ & 25(6.8) & $0(0)$ \\
\hline & With spouse & $121(33)$ & $41(11.2)$ & $80(21.9)$ & $0(0)$ \\
\hline & With children & $81(22.1)$ & $24(6.6)$ & $57(15.6)$ & $0(0)$ \\
\hline & With spouse and children & $111(30.2)$ & $7(1.9)$ & $100(27.3)$ & $3(0.8)$ \\
\hline & With others & $4(1.1)$ & $0(0)$ & $4(1.1)$ & $0(0)$ \\
\hline \multirow[t]{2}{*}{ Frequent hospitalization due to chronic illnesses } & Yes & 270(73.6) & $74(20.2)$ & $192(52.5)$ & $3(0.8)$ \\
\hline & No & $97(26.4)$ & $22(6)$ & $75(20.5)$ & $0(0)$ \\
\hline \multirow[t]{4}{*}{ Type of insurance } & Social security & 129(35.1) & $20(5.5)$ & 107(29.2) & $2(0.5)$ \\
\hline & Health services & 149(40.6) & $62(16.9)$ & $86(23.5)$ & $0(0)$ \\
\hline & Rural inhabitants insurance & $63(17.2)$ & 13(3.6) & $50(13.7)$ & $0(0)$ \\
\hline & Others & $26(7.1)$ & $1(0.3)$ & $24(6.6)$ & $1(0.3)$ \\
\hline
\end{tabular}


Table 1 Demographic characteristics of the older adults under hemodialysis experiencing different severities of elder abuse by family caregivers ( $n=367$ ) (Continued)

\begin{tabular}{|c|c|c|c|c|c|}
\hline \multirow[t]{2}{*}{ Variable } & \multirow[t]{2}{*}{ Subgroup } & \multirow{2}{*}{$\begin{array}{l}\text { Number } \\
\text { (\%) }\end{array}$} & \multicolumn{3}{|c|}{ Severity of elder abuse by family caregivers } \\
\hline & & & $\begin{array}{l}\text { Low } \\
1-75 \\
\text { Number (\%) }\end{array}$ & $\begin{array}{l}\text { Moderate } \\
76-152 \\
\text { Number (\%) }\end{array}$ & $\begin{array}{l}\text { Extreme } \\
153-228 \\
\text { Number (\%) }\end{array}$ \\
\hline \multirow[t]{3}{*}{ Experience of hemodialysis (months) } & $24>$ & $120(32.8)$ & $15(4.1)$ & $103(28.1)$ & $2(0.5)$ \\
\hline & $24-48$ & $109(29.5)$ & $42(11.2)$ & $67(18.3)$ & $0(0)$ \\
\hline & $48<$ & 138(37.7) & $40(10.9)$ & $97(26.5)$ & $1(0.3)$ \\
\hline \multirow[t]{2}{*}{ Experience of Drug abuse } & Yes & $44(12)$ & $19(5.2)$ & $25(6.8)$ & $0(0)$ \\
\hline & No & $323(88)$ & $77(21)$ & $242(66.1)$ & $3(0.8)$ \\
\hline \multirow[t]{4}{*}{ Financial Adequacy } & Adequate & $41(11.2)$ & $20(5.5)$ & $21(5.7)$ & $0(0)$ \\
\hline & Average & 168(45.8) & $44(12)$ & 122(33.3) & $1(0.3)$ \\
\hline & Low & $78(21.3)$ & 13(3.6) & $63(17.2)$ & $2(0.5)$ \\
\hline & Not adequate & $80(21.8)$ & $19(5.2)$ & $61(16.7)$ & $0(0)$ \\
\hline \multirow[t]{5}{*}{ Ability of doing personal activities } & Completely & $15(4.1)$ & $2(0.5)$ & 13(13.6) & $0(0)$ \\
\hline & A lot & $64(17.4)$ & $16(4.4)$ & $46(12.6)$ & $2(0.5)$ \\
\hline & Average & 145(39.5) & $51(13.9)$ & $92(25.1)$ & $1(0.3)$ \\
\hline & Low & $101(27.5)$ & $23(6.3)$ & $78(21.3)$ & $0(0)$ \\
\hline & Not much & $42(11.4)$ & $4(1.1)$ & $38(10.4)$ & $0(0)$ \\
\hline \multirow[t]{5}{*}{ Need for daily care } & Very much & $49(13.4)$ & $5(1.4)$ & $44(12)$ & $0(0)$ \\
\hline & A lot & 115(31.3) & $30(8.2)$ & $85(23.2)$ & $0(0)$ \\
\hline & Low & $121(33)$ & $26(7.1)$ & $93(25.4)$ & $2(0.5)$ \\
\hline & Not much & $65(17.7)$ & $31(8.5)$ & $32(8.7)$ & $1(0.3)$ \\
\hline & Not at all & $17(4.6)$ & $4(1.1)$ & 13(3.6) & $0(0)$ \\
\hline \multirow[t]{2}{*}{ Having other chronic illnesses } & Yes & $230(62.7)$ & $63(17.2)$ & $166(45.4)$ & $1(0.3)$ \\
\hline & No & 137(37.3) & $33(9)$ & $101(27.6)$ & $2(0.5)$ \\
\hline \multirow[t]{2}{*}{ Head of family } & Yes & 202(55) & $56(15.3)$ & 144(39.3) & $1(0.3)$ \\
\hline & No & $165(45)$ & $40(10.9)$ & 123(33.6) & $2(0.5)$ \\
\hline \multirow[t]{2}{*}{ Membership in hemodialysis association } & Yes & 297(80.9) & $91(24.9)$ & $204(55.7)$ & $1(0.3)$ \\
\hline & No & $70(19.1)$ & $5(1.4)$ & $63(17.2)$ & $2(0.5)$ \\
\hline
\end{tabular}

Independent variables (demographic, clinical, and care pressure variables) were entered in model 6 . The level of education entered the first model, explaining $27 \%$ of the changes in elderly abuse by family caregivers. Also, in models 2 to 6 , the variables of care burden, medical sciences-related education, chronic diseases, number of family members and marital status were entered, respectively, and finally explained $43 \%$ of changes in the subject. These variables have been also able to make significant predictions for elder abuse by family caregivers. The results showed that the level of education and care burden with the standard beta coefficient of -0.251 and 0.200 , respectively, have the highest regression effect on elder abuse by family caregivers (Table 6).

Stepwise Method multiple regression was used to investigate the simultaneous effect of variables related to older people under hemodialysis affecting elder abuse by family caregivers. Independent variables (demographic and clinical variables for the older adults and IADL) were entered in 8 models. The level of education entered the first model, explaining $34 \%$ of the changes in elder abuse by family caregivers. Also, in models 2 to 8 , IADL variables, with whom the older adult lives, ability of doing personal activities, financial adequacy, number of children, having other chronic diseases and age entered the model, which all explained $52 \%$ of the changes to the subject. These variables had also the potential to provide significant predictions for elder abuse by caregivers. The results showed that the level of education of the older adults and IADL with the standard beta coefficient of -0.299 and -0.234 , respectively, had the highest regression effect on the elder abuse (Table 7).

In this study, SEM method was used to test the proposed model (Model 1) and the effect of independent demographic and clinical variables of both groups (Fig. 1) 
Table 2 Individual characteristics of family caregivers by severity of care burden $(n=367)$

\begin{tabular}{|c|c|c|c|c|c|}
\hline \multirow[t]{2}{*}{ Variable } & \multirow[t]{2}{*}{ Subgroup } & \multirow{2}{*}{$\begin{array}{l}\text { Number } \\
\text { (\%) }\end{array}$} & \multicolumn{3}{|c|}{ Severity of Care Burden } \\
\hline & & & $\begin{array}{l}\text { Low } \\
0-20 \\
\text { Number (\%) }\end{array}$ & $\begin{array}{l}\text { Moderate } \\
21-40 \\
\text { Number (\%) }\end{array}$ & $\begin{array}{l}\text { Extreme } \\
41-88 \\
\text { Number } \\
(\%)\end{array}$ \\
\hline \multirow[t]{4}{*}{ Age (years) } & $30>$ & $22(6)$ & $13(3.5)$ & $4(1.1)$ & $5(1.4)$ \\
\hline & $50-30$ & 174(47.4) & $71(19.3)$ & $70(19.1)$ & $33(9)$ \\
\hline & $70-51$ & $150(40 / 9)$ & $57(15.5)$ & $60(16.3)$ & $33(9)$ \\
\hline & $71<$ & $21(5.7)$ & $11(3)$ & $8(2.2)$ & $2(0.5)$ \\
\hline \multirow[t]{2}{*}{ Sex } & Female & 238(64.9) & $58(15.8)$ & $44(12)$ & $27(7.4)$ \\
\hline & Male & 129(35.1) & $94(25.6)$ & $98(26.7)$ & $46(12.5)$ \\
\hline \multirow[t]{4}{*}{ Marital status } & Single & 49(13.4) & $21(5.7)$ & $18(4.9)$ & $10(2.7)$ \\
\hline & Married & 293(79.8) & 122(33.2) & 118(32.2) & $53(14.4)$ \\
\hline & Divorced & $14(3.8)$ & $3(0.8)$ & $5(1.4)$ & $6(1.6)$ \\
\hline & Widow & $11(3)$ & $6(1.6)$ & $1(0.3)$ & $4(1.1)$ \\
\hline \multirow[t]{4}{*}{ Level of Education } & Illiterate & $81(22.1)$ & $30(8.2)$ & $33(9)$ & $18(4.9)$ \\
\hline & Primary School & $74(20.2)$ & $31(8.4)$ & $28(7.6)$ & $15(4.1)$ \\
\hline & High School & 118(32.2) & 40(10.9) & $46(12.5)$ & $32(8.7)$ \\
\hline & University Degree & $94(25.6)$ & $51(13.9)$ & $35(9.5)$ & $8(2.2)$ \\
\hline \multirow[t]{2}{*}{ Medical Sciences-related Education } & Yes & $41(11.2)$ & $21(5.7)$ & $14(3.8)$ & $6(1.6)$ \\
\hline & No & $326(88.8)$ & $131(35.7)$ & 128(34.9) & $67(18.3)$ \\
\hline \multirow[t]{7}{*}{ Relationship with the Patient } & Father & $2(5)$ & $1(0.3)$ & $1(0.3)$ & $0(0)$ \\
\hline & Mother & $10(2.7)$ & $8(2.2)$ & $1(0.3)$ & $1(0.3)$ \\
\hline & Spouse & $143(39)$ & $59(16.1)$ & $64(17.4)$ & 20(5.4) \\
\hline & Sister & $6(1.6)$ & $3(0.8)$ & $1(0.3)$ & $2(0.5)$ \\
\hline & Brother & $3(0.8)$ & $3(0.8)$ & $0(0)$ & $0(0)$ \\
\hline & Child & $166(45.2)$ & $57(15.5)$ & $63(17.2)$ & $46(12.5)$ \\
\hline & Others & $37(10.1)$ & $21(5.7)$ & $12(3.3)$ & $4(1.1)$ \\
\hline \multirow[t]{3}{*}{ Duration of Care (months) } & $24>$ & 128(34.9) & $48(13.1)$ & $58(15.8)$ & $22(6)$ \\
\hline & $24-48$ & $92(25.1)$ & $18(4.9)$ & $61(16.6)$ & $13(3.5)$ \\
\hline & $48<$ & 147(40.1) & $56(15.3)$ & 73(19.9) & $18(4.9)$ \\
\hline \multirow[t]{2}{*}{ Caring another Patient? } & Yes & $29(7.9)$ & $6(1.6)$ & $18(4.9)$ & $5(1.4)$ \\
\hline & No & 338(92.1) & 146(39.8) & 124(33.8) & $68(18.5)$ \\
\hline \multirow[t]{2}{*}{ Having a Chronic disease } & Yes & $94(25.6)$ & $36(9.8)$ & $33(9)$ & $25(6.8)$ \\
\hline & No & $273(74.4)$ & 116(31.6) & 109(29.7) & $48(13.1)$ \\
\hline \multirow[t]{2}{*}{ Residence } & Urban & $222(60)$ & 107(29.2) & 72(19.6) & $41(11.2)$ \\
\hline & Rural & $145(40)$ & $44(12)$ & 69(18.8) & $30(8.2)$ \\
\hline \multirow[t]{2}{*}{ Housing Status } & Renting & $63(17.2)$ & $22(6)$ & $22(6)$ & $19(5.2)$ \\
\hline & Owning & 304(82.8) & 130(35.4) & $120(32.7)$ & $54(14.7)$ \\
\hline \multirow[t]{7}{*}{ Occupation } & Unemployed & $30(8.2)$ & $6(1.6)$ & $15(4.1)$ & $9(2.5)$ \\
\hline & Farmer & $26(7.1)$ & $10(2.7)$ & $11(3)$ & $5(1.4)$ \\
\hline & Housekeeper & 145(39.5) & $58(15.8)$ & $58(15.8)$ & $29(7.9)$ \\
\hline & Labor & $21(5.7)$ & $3(0.8)$ & $9(2.5)$ & $9(2.5)$ \\
\hline & Employee & $36(9.8)$ & $18(4.9)$ & $11(3)$ & $7(1.9)$ \\
\hline & Self-Employed & 49(13.4) & $26(7.1)$ & $15(4.1)$ & $8(2.2)$ \\
\hline & Retired & 47(12.8) & $22(6)$ & $19(5.2)$ & 6(1.6) \\
\hline
\end{tabular}


Table 2 Individual characteristics of family caregivers by severity of care burden ( $n=367$ ) (Continued)

\begin{tabular}{|c|c|c|c|c|c|}
\hline \multirow[t]{2}{*}{ Variable } & \multirow[t]{2}{*}{ Subgroup } & \multirow{2}{*}{$\begin{array}{l}\text { Number } \\
\text { (\%) }\end{array}$} & \multicolumn{3}{|c|}{ Severity of Care Burden } \\
\hline & & & $\begin{array}{l}\text { Low } \\
0-20 \\
\text { Number (\%) }\end{array}$ & $\begin{array}{l}\text { Moderate } \\
21-40 \\
\text { Number (\%) }\end{array}$ & $\begin{array}{l}\text { Extreme } \\
41-88 \\
\text { Number } \\
\text { (\%) }\end{array}$ \\
\hline & Student & $13(3.5)$ & $9(2.5)$ & $4(1.1)$ & $0(0)$ \\
\hline \multirow[t]{2}{*}{ Being the family income source } & Yes & $155(42)$ & $61(16.6)$ & $62(16.9)$ & 29(7.9) \\
\hline & No & $212(58)$ & $87(23.7)$ & $80(21.8)$ & $43(11.7)$ \\
\hline \multirow[t]{3}{*}{ Number of family members } & $<3$ & 137(37.3) & 69(18.8) & $49(13.4)$ & $19(5.2)$ \\
\hline & $4-3$ & $163(44.4)$ & 64(17.4) & $60(16.3)$ & $39(10.6)$ \\
\hline & $>4$ & $67(18.3)$ & $19(5.2)$ & 33(9) & $15(4.1)$ \\
\hline \multirow[t]{2}{*}{ Living with the patient } & Yes & $276(75.2)$ & 105(28.6) & 114(31.1) & $57(15.5)$ \\
\hline & No & $91(24.9)$ & $47(12.8)$ & $28(7.6)$ & $16(4.4)$ \\
\hline
\end{tabular}

on the relationship between care burden and IADL with elder abuse.

The normal distribution of data, outliers and missing data To examine the research hypotheses before using the SEM method, the assumptions of this method were examined. For this purpose, single-variable and multivariable data distribution were examined separately for natural distribution and discarded data. The existence of multivariate scatter data using Mahalanobis d-squared method $(P<0.001)$ and normal multivariate distribution using Mardia coefficient (above 20) were investigated [28]. The results showed that the normal single- and multivariate-distribution were normal.

Then, the fitness of the proposed model was evaluated based on the fitness indicators introduced in Table 8. Given that the value of CMIN/DF is less than 5 [29] and the value of SRMR is less than 0.1 [30], the fitness of the proposed model is confirmed. To improve the fitness of the proposed model, the model was modified in the next step by drawing a correlation between the errors.
The results showed that the two variables of care burden and IADL explained $43 \%$ of the changes in elder abuse by family caregivers in the model. Standard regression coefficients showed that there was a strong negative relationship between IADL and elder abuse by family caregivers. Therefore, the greater the independence of the older adults, the lower the rate of elder abuse abuse $(\beta=0.12)$. There is also a positive and strong relationship between care burden and elderly abuse by family caregivers. As the care burden increases, the abuse increases $(\beta=0.20)$ (Model 1$)$.

The structural function model after data fit with the assumed pattern is shown in Fig. 1 according to the demographic and clinical variables related to the older adults and related to the family caregiver. The results showed that the demographic and clinical variables related to the older adults, with whom the older adult lives $(r=0.29, P$-value $<0.001)$, age $(r=0.14, P$-value $<0.05)$, other chronic diseases $(r=0.10, P$-value $<0.05)$ and the number of children $(r=0.20, P$-value $<0.001)$ have a positive effect on the elder abuse respectively. However, the level of education $(r=-0.28, P$-value $<0.001)$ and

Table 3 Number and percentage of scores of elder abuse by caregivers and its aspects by the severity of elder abuse $(n=367)$

\begin{tabular}{lcccc}
\hline $\begin{array}{l}\text { Elder abuse by caregivers } \\
\text { and its aspects }\end{array}$ & Mean \pm SD & \multicolumn{2}{l}{ severity of elder abuse by caregivers } \\
\cline { 3 - 5 } & & $\begin{array}{l}\text { Low } \\
\text { Number (\%) }\end{array}$ & $\begin{array}{l}\text { Moderate } \\
\text { Number (\%) }\end{array}$ & $\begin{array}{l}\text { Extreme } \\
\text { Number (\%) }\end{array}$ \\
\hline Psychological Misbehavior & $10.86 \pm 3.07$ & $71(19.2)$ & $245(66.8)$ & $51(14)$ \\
Authority Deprivation & $12.70 \pm 3.23$ & $60(16.3)$ & $263(71.7)$ & $44(12)$ \\
Physical Misbehavior & $3.49 \pm 1.08$ & $103(28.1)$ & $247(67.3)$ & $17(4.6)$ \\
Financial Misbehavior & $19.07 \pm 5.33$ & $94(25.6)$ & $242(65.9)$ & $31(8.5)$ \\
Being Abandoned & $7.15 \pm 2.14$ & $91(24.8)$ & $234(63.8)$ & $42(11.4)$ \\
Caring Neglect & $13.06 \pm 4.40$ & $79(21.5)$ & $262(71.4)$ & $26(7.1)$ \\
Emotional Misbehavior & $21.46 \pm 6.09$ & $254(69.2)$ & $97(26.4)$ & $16(4.4)$ \\
Total & $87.89 \pm 19.75$ & $96(26.2)$ & $257(70)$ & $14(3.8)$ \\
\hline
\end{tabular}


Table 4 Average, standard deviation and frequency distribution of care burden severity and its aspects by levels

\begin{tabular}{|c|c|c|c|c|}
\hline \multirow[t]{2}{*}{ Care burden and its aspects } & \multirow[t]{2}{*}{ Mean \pm SD } & \multicolumn{3}{|c|}{ Severity of care burden } \\
\hline & & $\begin{array}{l}\text { Low } \\
\text { Number (\%) }\end{array}$ & $\begin{array}{l}\text { Moderate } \\
\text { Number (\%) }\end{array}$ & $\begin{array}{l}\text { Extreme } \\
\text { Number (\%) }\end{array}$ \\
\hline Role Related stress & $22.61 \pm 8.75$ & $109(29.7)$ & $226(61.6)$ & $32(8.7)$ \\
\hline Intra-Psychic Stress & $13.41 \pm 5.86$ & $96(26.2)$ & $221(60.2)$ & $50(13.6)$ \\
\hline Competencies \& Expectations & $12.69 \pm 4.11$ & $101(27.5)$ & $226(61.6)$ & $40(10.9)$ \\
\hline Total & $48.63 \pm 16.74$ & $94(25.6)$ & $232(63.2)$ & $41(11.2)$ \\
\hline
\end{tabular}

financial adequacy $(r=-0.10, P$-value $<0.05)$ have negative effects. Therefore, the higher the level of education and financial independence of the older adults, the more we will see a decrease in the elder abuse by family caregivers. Also, demographic variables related to family caregiver $(r=-0.19, P$-value $<0.05)$ and marital status $(r=-$ $0.68, P$-value $<0.001)$ have a negative effect on the subject, respectively. Therefore, the higher the level of caregiver's education, the lower the rate of elderly abuse. But there is no significant relationship between the number of family members caring for the older adults and the elder abuse.

\section{Discussion}

The objectives of this study were to determine the prevalence of elder abuse by family caregivers among older patients under hemodialysis and the factors affecting it. Overall, the results showed that more than half of the older adults under hemodialysis suffered from moderate abuse by their family caregivers, and patient's level of education, IADL scores, caregivers' level of education and his/her marital status had the highest regression effect on the elder abuse. Different information is available on the prevalence of elder abuse by family caregivers. For example, in the study of Orfila et al. (2018), the

Table 5 Mean, standard deviation and frequency distribution of IADL and its dimensions by sex

\begin{tabular}{|c|c|c|c|}
\hline IADL & Sex & & Mean \pm SD \\
\hline \multirow[t]{2}{*}{ Using of Telephone } & Female & & $1.19 \pm 0.73$ \\
\hline & Male & & $1.37 \pm 0.69$ \\
\hline \multirow[t]{2}{*}{ Shopping } & Female & & $0.89 \pm 0.81$ \\
\hline & Male & & $1.08 \pm 0.77$ \\
\hline \multirow[t]{2}{*}{ Meal Preparation } & Female & & $0.96 \pm 0.80$ \\
\hline & Male & & 0 \\
\hline \multirow[t]{2}{*}{ Housekeeping } & Female & & $0.85 \pm 0.72$ \\
\hline & Male & & 0 \\
\hline \multirow[t]{2}{*}{ Laundry } & Female & & $0.80 \pm 0.81$ \\
\hline & Male & & 0 \\
\hline \multirow[t]{2}{*}{ Mode of Transportation } & Female & & $0.96 \pm 0.79$ \\
\hline & Male & & $0.96 \pm 0.85$ \\
\hline \multirow[t]{2}{*}{ Medication Management } & Female & & $1.28 \pm 0.74$ \\
\hline & Male & & $1.42 \pm 0.66$ \\
\hline \multirow[t]{2}{*}{ Money Management } & Female & & $0.74 \pm 0.85$ \\
\hline & Male & & $1.07 \pm 0.80$ \\
\hline \multirow[t]{8}{*}{ Total } & Female & Number of completely dependent (0) cases (\%) & $11(6.2)$ \\
\hline & & Number of cases needing help (1-15) (\%) & 145(81.4) \\
\hline & & Completely independent (16) (\%) & $22(12.4)$ \\
\hline & & total score & $7.68 \pm 4.85$ \\
\hline & Male & Number of completely dependent (0) cases (\%) & $9(4.7)$ \\
\hline & & Number of cases needing help (1-9) (\%) & 152(80.5) \\
\hline & & Completely independent (10) (\%) & 28(14.7) \\
\hline & & Total score & $6.66 \pm 3.62$ \\
\hline
\end{tabular}


Table 6 The final model (sixth model) of regression of the effect of independent variables (related to family caregivers) on the dependent variable (elder abuse)

\begin{tabular}{|c|c|c|c|c|c|}
\hline Model & Unstandardized Coefficients B & Std. Error & Standardized Coefficients Beta & $\mathbf{t}$ & Sig \\
\hline Constant & 68.626 & 9.141 & & 7.508 & 0.000 \\
\hline Level of education & -4.540 & 0.927 & -0.251 & -4.997 & 0.000 \\
\hline Care burden & 0.236 & 0.058 & 0.200 & 4.094 & 0.000 \\
\hline Medical sciences-related education & 8.938 & 3.128 & 0.143 & 2.857 & 0.005 \\
\hline Having chronic diseases & 5.380 & 2.188 & 0.119 & 2.459 & 0.014 \\
\hline Number of family members & 1.796 & 0.744 & 0.118 & 2.415 & 0.016 \\
\hline Marital status & -3.718 & 1.786 & -0.102 & -2.082 & 0.038 \\
\hline The summary of the 6 th model &,$F=48.105 P<0.001$ & & R-square $=0.496$ & adjuste & yuare $=0.428$ \\
\hline
\end{tabular}

prevalence of the subject was $33.4 \%$ [18] but the same number at the American studies is reported to be 5$10 \%$ [31-33]. Manouchehri et al.'s (2008) study also found that more than $87 \%$ of respondents were at least once abused by family caregivers [34]. Such differences can be attributed to different research approaches, target groups, and data collection tools.

The highest median elder abuse was related to the emotional aspect. Negative reactions from family caregivers to the symptoms and consequences of CKD or related therapies such as hemodialysis, and expressing disgust as touching the central venous catheter or arterial-venous fistula, or feeling ashamed and therefore not accompanying the older adults in public places due to disease-related appearance changes, and ignoring physical contact with the older adults for fear of contagious disease are among the cases of emotional elder abuse by family caregivers. The high level of emotional abuse can be due to the ignorance of caregivers about how to establish respectful relationships and maintain human dignity with the older adults. The results of other studies showed that the highest score of elder abuse was related to the mental aspect. In Manouchehr et al.'s
(2008) research, emotional abuse and negligence have been the most common forms of abuse [34]. In Nouri et al.'s (2013) study, $34.8 \%$ of the older adults experienced emotional negligence [35].

The results showed that the level of education of the older adults and IADL had the highest regression effect on elder abuse. This means that with a unit increase in the level of education of the older adults and IADL scores, 0.251 and 0.234 units of decrease are observed in elder abuse, respectively. A high level of education in the older adults may cause them to be able to take better care of themselves and put less pressure on their caregivers. This finding is inconsistent with the results of a study by Orfila et al. (2018) [18]. Decreased energy levels, frequent need for hemodialysis and associated health problems, feelings of depression, and inability to perform normal daily activities, all affect the patient and disrupt his normal life and increase his dependence on family caregivers [24]. When the older adults become dependent on family caregivers for a variety of reasons, his self-care and self-management abilities get limited. In fact, time-consuming and tedious activities such as transporting the older adults to dialysis centers, caring

Table 7 The final regression model (8th model) of the effect of independent variables (related to the older adult) on the dependent variable (elder abuse)

\begin{tabular}{|c|c|c|c|c|c|}
\hline Model & Unstandardized Coefficients B & Std.Error & Standardized Coefficients Beta & $\mathbf{t}$ & Sig \\
\hline Constant & 66.848 & 7.817 & & 8.551 & 0.000 \\
\hline Level of education & -4.160 & 0.720 & -0.299 & -5.780 & 0.000 \\
\hline IADL & -4.283 & 0.833 & -0.234 & -5.143 & 0.000 \\
\hline With whom the older adult lives & 8.525 & 1.806 & 0.211 & 4.720 & 0.000 \\
\hline Ability of doing daily activities & -2.646 & 0.986 & -0.135 & -2.683 & 0.008 \\
\hline Financial adequacy & 2.568 & 0.978 & 0.124 & 2.627 & 0.009 \\
\hline Number of children & 3.433 & 1.088 & 0.157 & 3.156 & 0.002 \\
\hline Having other chronic diseases & 4.740 & 1.901 & 0.116 & 2.493 & 0.013 \\
\hline Age & -1.648 & 0.786 & -0.104 & -2.098 & 0.037 \\
\hline The summary of the 6 th model & $F=62.5410 .001, P<$ & & OR-square $=0.559$ & \multicolumn{2}{|c|}{ adjusted- R-square $=0.517$} \\
\hline
\end{tabular}




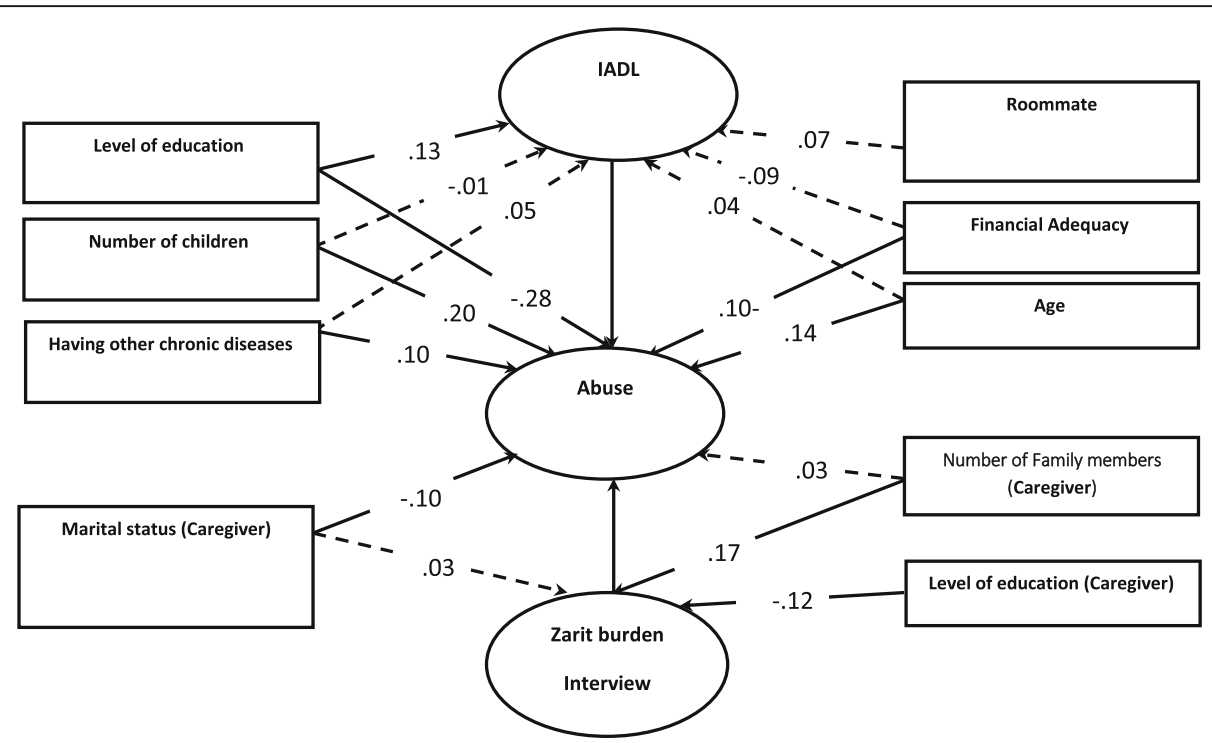

Fig. 1 Structural Equation Modeling Results: The Relationship between Care burden and IADL with elder abuse by Family Caregivers Based on Demographic and Clinical Variables

for the older adults after dialysis, controlling blood pressure, injecting insulin in cases where the patient has diabetes, controlling the proper and timely use of oral medications, Preparing and supervising the nutrition of the older adults and helping him with many of the daily activities of his life, such as bathing, making food, shopping, etc., will be among the duties of family caregivers. In most cases, these tasks and associating them with tasks related to the personal and family life of caregivers imposes a lot of pressure on them, which sometimes leads to misbehavior with the older adults due to lack of social support and support from other family members[24, 26]. The results of a study by Dastyar et al. (2020) showed that there is a significant relationship between the need for care and the suffering of care. In a way, the more the patient needs care, the more the caregiver suffers. This suggests that the worse the functional level of patients and the greater their need and dependence on caregivers, the greater the suffering caused by this dependence in caregivers and more possibility of negligence [36].

The results showed that $63.2 \%$ of family caregivers experienced moderate care burden. The results of the present study showed that there is a significant relationship between care burden and elder abuse. A study by Iborra et al. (2008) also showed that the negative effects of caring for dependent relatives such as caring burden, stress, mood disorders, social isolation and caregiver's personality are effective factors in elder abuse by family caregivers [37]. The results showed that the level of caregiver's education and care burden had the highest regression effect on elder abuse by family caregivers. The results of a study by Dastyar et al. (2020) showed that caregivers who had a higher level of education and were employed reported less care suffering than caregivers with lower education and unemployed [36]. The results of a study by Orfila et al. (2018) showed that the most relevant risk factors for elder abuse by family caregivers were the care burden, caregiver's anxiety, caregiver perception of aggressive behavior in the care recipient, and bad previous relationship respectively [18].

The results of the present study showed that the demographic variables related to family caregivers, respectively, the level of caregiver education and marital status, have a negative effect on elder abuse. Therefore, the higher the level of caregiver education, the lower the possibility of abuse. A higher level of education is likely to increase understanding of the conditions and needs of hemodialysis patients and increase the financial independence of the caregiver, thus making it less difficult to provide care services to older people. Married caregivers may also be more tolerant of the burden of care due to

Table 8 Fit indices of the primary and modified model

\begin{tabular}{|c|c|c|c|c|c|c|c|c|}
\hline & GFI & $\mathrm{NFI}$ & CFI & SRMR & CMIN/DF & P-Value & Df & CMIN \\
\hline Primary model & 0.841 & 0.887 & 0.897 & 0.084 & 4.42 & $<0.001$ & 134 & 592.362 \\
\hline Modified model & 0.970 & 0.951 & 0.967 & 0.041 & 2.83 & $<0.001$ & 126 & 357.593 \\
\hline
\end{tabular}

Abbreviations; CMIN/DF Chi-square/degree-of-freedom ratio; SRMR Standardized Root Mean Squared Residual; GFI Goodness of Fit Index; NFI Normed Fit Index; CFI Comparative Fit Index. Fit indices: CFI, NFI, GFI ( $>0.9)$, SRMR (<0.05 good, 0.05-0.08 accept), CMIN/DF (<3 good, <5 acceptable) 
their higher sense of responsibility to their parents than to single people. The level of education in the results of the studies of Dastyar et al. (2020) [36] and Ashghali Farahani et al. (2016) [38] is also a factor in predicting the care burden and ultimately elder abuse by family caregivers.

The limitations of this study include the following: Due to the prevailing culture in Iranian society regarding the preservation of the dignity of the family and children, it may have not been possible for the patients to respond to the items freely. Convenience sampling method was used in this study. This method will impair the generalizability of the results. The study's target group was older adults under hemodialysis and their family caregivers. Due to the nature of the disease, the participating patients may have experienced different abusing severities in different dimensions rather than the older people with other chronic diseases, so the results can only be generalized to this group of older adults and their family caregivers. The study used the elder abuse by family caregivers' questionnaire to investigate the elder abuse and its dimensions. The data collected with this tool cannot confirm whether or not the abuse actually occurred. However, we consider it the best tool available to achieve the goal of our study because it has acceptable validity and reliability for measuring the structure we want. Understanding elder abuse by family caregivers varies from culture to culture, so generalizing the results may impair them. Given the selfreported nature of the abuse questionnaire, the likelihood of the older adults feeling guilty about talking about the subject and the problems they endure can affect the prevalence and severity of the phenomenon.

\section{Conclusions}

The results of the present study showed that the prevalence of elder abuse by family caregivers among the older adults under hemodialysis is high.

Health and social policymakers can reduce the prevalence of elder abuse by the application of different programs such as requiring the screening of elder abuse, raising people's awareness through media, mandatory reporting of abuse by healthcare professionals (HCPs), training programs for older adults, their family caregivers, and HCPs to identify the phenomenon of elder abuse, factors affecting it and how to deal with it. implementation of educational programs with the purpose of increasing self-confidence of the older people and development of support systems, which aim to reduce the prevalence of elder abuse and manage the effective factors in it, can be also listed as the aforementioned programs. Furthermore, providing psychological counseling, especially when the patient is referred to a medical center for hemodialysis, can reduce the consequences of elder abuse. The best time to train caregivers is when they are with the older adults in medical centers and hemodialysis departments. HCPs can develop and implement training and counseling programs to achieve the goal of reducing elder abuse at a time when the older adults are hospitalized for at least 3 to $4 \mathrm{~h}$.

The results of the present study showed that one of the effective factors in elder abuse is the care burden. In the first step, intervention programs should be developed to reduce the care burden of family caregivers. Community support services need to be designed so that family caregivers can take advantage of the care they receive. Psychological interventions for family caregivers, such as participating in community support groups, getting help from formal caregivers, and getting help from other family members may reduce their care burden.

The results of the study showed that the dependence of the older adults on caregivers is associated with an increase in elder abuse cases. Primary prevention activities should be developed continuously and based on the community and the family in order to reduce the risk factors for the elder abuse. Interventions such as training on how to care for the older adults, financial assistance for cases with complete dependence through centers such as state welfare organization and adequate social support for caregivers may reduce the factors affecting the elder abuse.

The strengths of this study include the following: The results of this study, due to the high number of samples, provide a relatively broad view of the prevalence and factors influencing the elder abuse by family caregivers among the older adults under hemodialysis. The results of this study can help health policy makers to develop and implement care programs for older people experiencing hemodialysis. Using the SEM method to test the relationship between the studied variables.

\section{Abbreviations}

WHO: World health organization; CKD: Chronic Kidney Disease; HD: Hemodialysis; SEM: Structural Equation Modeling; HCPs: Healthcare professionals; CMIN/DF: Chi-square/degree of freedom ratio; NFI: Normed Fit Index; CFI: Comparative fit index; GFI: Goodness of fit index;

SRMR: Standardized root mean squared residual

\section{Supplementary Information}

The online version contains supplementary material available at https://doi. org/10.1186/s12877-021-02291-x.

Additional file 1: Model 1. Standard coefficients of the modified model

Acknowledgements

We would like to thank all the older adults under hemodialysis and their family caregivers, as well as the officials of the medical centers in the west of Mazandaran province and the east of Gilan province. 


\section{Authors' contributions}

A.M. researched data. F.GH. wrote the manuscript and researched data. A.SH. reviewed/edited the manuscript. A.A. and Z.F. contributed to discussion and reviewed/edited the manuscript. F.GH. and A.M. researched data and contributed to discussion. All authors read and agreed the final submitted manuscript.

\section{Funding}

The study was funded by the Babol University of Medical Sciences. The funder had no role in study design, data collection and analysis, decision to publish, or preparation of the manuscript.

\section{Availability of data and materials}

Data generated or analysed during this study are included in this published article and are available from the corresponding author on reasonable request.

\section{Declarations}

\section{Ethics approval and consent to participate}

Permission was obtained from the Ethics Committee of Babol University of Medical Sciences (IR.MUBABOL.HRI.REC.1394.177.). Objectives and research methods were explained to the participants. The Conscious Satisfaction Form was completed by the participants they were explained about their right for leaving the study at any stage. Obtaining written consent form from the samples. The principles of confidentiality of information were observed and the participants' names were not inserted on any tool at any stage of the study. The methods involved in our research are carried out in accordance with relevant guidelines and regulations (Declaration of Helsinki).

\section{Consent for publication}

Not applicable.

\section{Competing interests}

The authors report no conflicts of interest in this work.

\section{Author details}

${ }^{1}$ Golestan University of Medical Sciences, Gorgan, Iran. ${ }^{2}$ Nursing Care Research Center, Health Research Institute, Babol University of Medical Sciences, Shahid Motahari St, Ramsar, Mazandaran, Ramsar, Iran. ${ }^{3}$ Nursing Care Research Center, Health Research Institute, Babol University of Medical Sciences, Babol, Iran. ${ }^{4}$ Imam Sajjad Hospital, Mazandaran University of Medical Sciences, Mazandaran, Ramsar, Iran.

\section{Received: 29 July 2020 Accepted: 18 May 2021}

\section{Published online: 12 June 2021}

\section{References}

1. Department of economic and social affairs. Population division. World population ageing. 2015. United Nations. New York, 2015. Available from: https://www.un.org/en/development/desa/population/publications/pdf/a geing/WPA2015_Highlights.pdf.

2. Ghiasi A. Prevalence of elder abuse and neglect in Iran: A systematic review and meta-analysis. Shiraz E-Medical Journal. 2018;19(11):e81045. doi:https:// doi.org/10.5812/semj.81045.

3. Molaei M, Etemad K, Taheri Tanjani P. Prevalence of elder abuse in Iran: a systematic review and meta analysis. Iranian Journal of Ageing. 2017;12(2): 242-53.

4. Heravi-Karimooi M, Rejeh N, Montazeri A. Health-related quality of life among abused and non-abused elderly people: a comparative study. Payesh (Health Monitor). 2013;12(5):479-88.

5. Dong $X Q$. Elder abuse: Systematic review and implications for practice. J Am Geriatr Soc. 2015;63(6):1214-38.

6. Lachs MS, Pillemer KA. Elder abuse. N Engl J Med. 2015;373(20):1947-56.

7. Aboozadeh Gotabi K, Ghanbari Moghaddam A, Mohammadi M, Zarei F. The burden of family caregivers caring for older adults and its relationship with some factors. Nursing of the Vulnerable Journal. 2016;3(6):27-36.

8. Sadrollahi A, Khalili Z, Ghorbani M, Mahmoodi M. The prevalence of various abuse types and their associated factors in the elderly. Journal of Research Health. 2020;10(1):59-66.
9. Adib-Hajbaghery M, Ahmadi B. Caregiver burden and its associated factors in caregivers of children and adolescents with chronic conditions. Int J Community Based Nurs Midwifery. 2019;7(4):258.269.

10. Reinhard SC, Given B, Petlick NH, Bemis A. Supporting Family Caregivers in Providing Care. In: Hughes RG, editor. Patient Safety and Quality: An Evidence-Based Handbook for Nurses. Rockville (MD): Agency for Healthcare Research and Quality (US); 2008. Chapter 14. PMID: 21328765.

11. Heravi Karimoei M, Reje N, Foroughan M, Montazeri A. Elderly abuse rates within family among members of senior social clubs in Tehran. Iranian Journal of Ageing. 2012;6(4):37-50.

12. Rahimi V, Heidari M, Nezarat S, Zahedi A, Mojadam M, Deris S. Factors related to elder abuse within the family. Quarterly Journal of Geriatric Nursing. 2016:3(1):89-100.

13. Heravi M, Anousheh M, Foroughan M, Sheikhi M, Hadjizadeh E. The meaning of domestic elderly abuse concept. Daneshvar Medicine: Basic Clinical Research Journal. 2010;16(6):39-50.

14. Yan E, Kwok T. Abuse of older Chinese with dementia by family caregivers: an inquiry into the role of caregiver burden. Int J Geriatr Psychiatry. 2011; 26(5):527-35.

15. Mahmoudian A, Chafjiri RT, Alipour A, Shamsalinia A, Ghaffari F. The design and evaluation of psychometric properties for a questionnaire on elderly abuse by family caregivers among older adults on hemodialysis. Clin Interv Aging. 2018;13:555-63.

16. Hamer RA, El Nahas AM. The burden of chronic kidney disease. BMJ. 2006; 332(7541):563-4.

17. Yunus RM, Hairi NN, Choo WY. Consequences of elder abuse and neglect: A systematic review of observational studies. Trauma Violence Abuse. 2019; 20(2):197-213

18. Orfila F, Coma-Solé M, Cabanas M, Cegri-Lombardo F, Moleras-Serra A, Pujol-Ribera E. Family caregiver mistreatment of the elderly: prevalence of risk and associated factors. BMC Public Health. 2018;18(1):1-14.

19. Esmat Saatlou M, Hossaini F, Sakeni Z. Assessment of elder abuse in adult day care centers. Journal of Geriatric Nursing. 2015;2(1):91-103.

20. Ghaffari F, Alipour A, Fotokian Z. The effects of education on nurses' ability to recognize elder abuse induced by family members. Nursing midwifery studies. 2020:9(1):1-8.

21. Alipour A, Fotokian Z, Shamsalinia A, Ghaffari F, Hajiahmadi M. The Relationship between Nurses' Recognition Regarding Elder Abuse and their Attitudes and Performance in Dealing with Elder Abuse Induced by Iranian Family Caregivers. The Open Nursing Journal. 2019;13(1):116-22.

22. Zarit SH, Zarit JM. The memory and behavior problems checklist and the burden interview. University Park: Pennsylvania State University, Gerontology Center.; 1987.

23. Bianchi M, Flesch LD, Alves EVdC, Batistoni SST, Neri AL. Zarit burden interview psychometric indicators applied in older people caregivers of other elderly. Rev lat Am enfermagem. 2016;24:e2835. doi:https://doi.org/1 0.1590/1518-8345.1379.2835.

24. Talebi M, Mokhtari Lakeh N, Rezasoltani P. Caregiver burden in caregivers of renal patients under hemodialysis. Journal of Holistic Nursing Midwifery. 2016;26(2):59-68.

25. Lawton M, Brody E, Médecin U. Instrumental activities of daily living (IADL). The gerontologist. 1969;9:179-86.

26. Mehraban AH, Soltanmohamadi Y, Akbarfahimi M, Taghizadeh G. Validity and reliability of the persian version of lawton instrumental activities of daily living scale in patients with dementia. Iranian Journal of Ageing. 2014;9(2):160-7.

27. Hoyle RH. Handbook of structural equation modeling: The Guilford Press; 2012. Available from: https://www.guilford.com/excerpts/hoyle.pdf?t.

28. Vinzi VE, Chin WW, Henseler J, Wang H. Handbook of partial least squares: Concepts, Methods and Applications. Springer; 2010.

29. Wilson TD, Lindsey S, Schooler TY. A model of dual attitudes. Psychological review. 2000;107(1):101-26.

30. Fabrigar $L R$, Wegener DT, MacCallum RC, Strahan EJ. Evaluating the use of exploratory factor analysis in psychological research. Psychol Methods. 1999; 4(3):272-99

31. Acierno RHM, Amstadter AB, Resnick HS, Steve K, Muzzy W, et al. Prevalence and correlates of emotional, physical, sexual, and financial abuse and potential neglect in the United States: The National Elder Mistreatment Study. Am j public health. 2010;100(2):292-7.

32. Laumann EOLS, Waite L. Elder mistreatment in the United States: Prevalence estimates from a nationally representative study. Gerontol B. Psychol Sci Soc Sci. 2008;63(4):248-54. 
33. Burnes DPK, Caccamise PL, Mason A, Henderson CR Jr, Berman J, et al. Prevalence of and risk factors for elder abuse and neglect in the community: a population-based study. J Am Geriatr Soc. 2015;63(9):1906-12.

34. Maneuchehry H, Ghorby B. The amount and types of domestic abuse in the elderly referred to Parks of Tehran. Journal of School of Nursing Midwifery Beheshti. 2008;18(62):37-43.

35. Nori A, Rajabi A, Esmailzadeh F. Prevalence of elder misbehavior in northern Iran. J Gorgan Univ Med Sci. 2013;16(4):93-8.

36. Dastyar NMF, Rafati F. Caregiving burden in hemodialysis patients' caregivers in Kerman Province: A descriptive-analytical study. Journal of Jiroft University of Medical Sciences. 2020;7(1):323-31.

37. Iborra I. Elder Abuse in the Family in Spain. Valencia: Fundación de la Comunitat Valenciana para el estudio de la violencia (Centro Reina Sofía); 2008. Available from: http://www.inpea.net/images/Espana_Informe_2008_ Maltrato.pdf.

38. Ghane GSN, Ashghali Farahani M, Hagani H. Effectiveness of supportive educative program on the burden in family caregivers of hemodialysis patients. The J Urmia Nurs Midwifery Fac. 2017;14(10):885-95.

\section{Publisher's Note}

Springer Nature remains neutral with regard to jurisdictional claims in published maps and institutional affiliations.

- fast, convenient online submission

- thorough peer review by experienced researchers in your field

- rapid publication on acceptance

- support for research data, including large and complex data types

- gold Open Access which fosters wider collaboration and increased citations

- maximum visibility for your research: over $100 \mathrm{M}$ website views per year

At $\mathrm{BMC}$, research is always in progress. 